\title{
A Pesquisa-Intervenção no Mestrado Profissional e suas possibilidades metodológicas
}

\section{Research-Intervention in the Professional Master's and its methodological possibilities}

\author{
Daianny Madalena Costa* \\ Ana Cristina Ghisleni*
}

\begin{abstract}
RESUMO
A pesquisa-intervenção é apresentada na dimensão da especificidade que assume na proposta de um Mestrado Profissional. Ao aproximar propostas de intervenção construídas pelas dissertações do Programa de Pós-Graduação em Gestão Educacional - Mestrado Profissional da Unisinos de elementos retirados de revisões bibliográficas pautadas por diferentes autores, o objetivo é discutir a importância e a configuração das propostas de intervenção em suas dimensões de compromisso ético, social e epistemológico. Evidenciase, com isso, um percurso de amadurecimentos e de desafios no que tange à constituição de uma metodologia atrelada a um campo de conhecimento que se robustece mais ainda o que está em construção.
\end{abstract}

Palavras-chave: Pesquisa-intervenção. Metodologia. Mestrado Profissional.

\begin{abstract}
The intervention research is presented in the dimension of specificity that it assumes in the proposal for a Professional Master's. When approaching intervention proposals constructed by the Graduate Program in Educational Management dissertations - Unisinos Professional Master's Degree from
\end{abstract}

* Universidade do Vale do Rio dos Sinos. São Leopoldo, Rio Grande do Sul, Brasil. E-mail: daiannyc@unisinos.br - https://orcid.org/0000-0001-7045-0259 E-mail: acghisleni@unisinos.br - https://orcid.org/0000-0002-1877-8182 
elements taken from bibliographic reviews guided by different authors, the objective is to discuss the importance and the configuration of the intervention proposals in their dimensions of ethical, social and epistemological commitment. With this, a path of maturation and challenges is evidenced concerning the methodology constitution linked to a knowledge field that is further strengthened and is still under construction.

Keywords: Search-intervention. Methodology. Professional Master's Degree.

O tema da "pesquisa em educação" tem sido objeto de análise desde os 1970 (GATTI, 1992). No exame realizado pela pesquisadora sobre esse assunto, foram encontrados 42 artigos, nos 79 Cadernos de Pesquisa publicados pela Fundação Carlos Chagas. À época, a autora realizou um conjunto de análises a fim de validar a hipótese da necessidade de maior rigor teórico-metodológico na constituição dos estudos educacionais.

Mazzotti (2003) problematizou a pesquisa em educação a partir das suas implicações com o cotidiano das escolas e das políticas. Dito de outra forma, o questionamento versava sobre como as pesquisas contribuem ou influenciam o contexto educacional. Em síntese, o estudo acerca do impacto da pesquisa em educação e sua relação com a melhoria nos seus vários campos de investigação - gestão, formação de professores, políticas educacionais, ensino, entre outros que são por ela problematizados. A partir disso, constatou que havia um reduzido uso/vinculação/aplicação entre as pesquisas realizadas e sua apropriação por professores, gestores e políticas.

A autora destacou dois elementos para esse distanciamento. O primeiro diz respeito aos problemas relacionadas às pesquisas efetivamente, pois elas carecem, em muitos momentos, de uma maior rigorosidade metodológica e teórica. Tal fato é compreendido como causa e efeito de problemas de pesquisa frágeis, o que gera consequência no desenvolvimento de toda a investigação. A isso, soma-se a própria construção epistemológica da formação docente, a qual se apoia em fazeres desconectados da teoria e, por vezes, ao contatar com pesquisas distantes do contexto escolar, não as reconhecem como importantes (MAZZOTTI, 2003).

Contribuindo para esse aspecto, Cunha (2019), ao analisar a docência universitária, insere uma interessante compreensão da pesquisa desenvolvida nesse âmbito. Para a autora, as dimensões e responsabilidades próprias da docência universitária estabelecem "uma perspectiva de saberes múltiplos e interligados", mas que estão vinculados a "uma cultura historicamente consolidada que define práticas e estruturas de poder" (CUNHA, 2019, p. 122). 
É igualmente importante mencionarmos o trabalho de Mainardes (2018), no qual o autor realiza uma metapesquisa a partir de 140 artigos publicados em sete periódicos nacionais, sobre o tema políticas educacionais, no periodo de 2010-2012. Em relação à perspectiva epistemológica como pressuposto para a análise feita nos artigos publicados, Mainardes conclui que apenas cinco trabalhos contemplaram a temática analisada.

No que tange ao lugar da pesquisa nos Mestrados Profissionais, parece-nos de extrema valia resgatar os escritos de André e Princepe (2017). Ali, as autoras resgatam a trajetória dos mestrados profissionais no Brasil, fazendo referência, inclusive, a momentos de tensionamento entre o acadêmico e o profissional. No entanto, ao tratar das aproximações e das diferenças entre o Mestrado Profissional e o Acadêmico, ambas acentuam o lugar privilegiado da pesquisa na formação do profissional da educação, enfatizando a importância da pesquisa-intervenção no campo do stricto sensu profissional.

O que se propõe é que o profissional seja um pesquisador de sua prática e, para isso, a formação deve estar toda ela orientada para a pesquisa, de modo que o trabalho final de conclusão seja o resultado dessa pesquisa. Nossa posição é que a pesquisa tem um importante papel na formação dos mestres profissionais em educação, pois lhes dá oportunidade de analisar a realidade em que se inserem, localizar áreas críticas que possam ser esclarecidas por um processo sistemático de coleta de dados e de referenciais teórico-metodológicos, que lhes permitam atuar mais efetivamente nessa realidade. A pesquisa quando promove a reflexão crítica sobre a prática profissional em educação possibilita o desenvolvimento de indivíduos críticos e criativos (ANDRÉ; PRINCEPE, 2017, p. 105-106).

Esses elementos concernentes à pesquisa estão inicialmente apresentados aqui para enfatizar o quanto as questões metodológicas são cruciais para a pesquisa em educação. Os objetivos que nos movem para propor a discussão acerca da pesquisa-intervenção, portanto, residem na problematização acerca dos aspectos metodológicos mais relevantes para a construção da intervenção, no contexto do mestrado profissional. Isso se torna ainda mais pertinente frente à portaria normativa, que regulamenta os mestrados profissionais (MPs), $\mathrm{n}^{\circ} 17$, de 28 de dezembro de 2009 (CAPES, 2009), da Coordenação de Aperfeiçoamento de Pessoal de Nível Superior (CAPES). Ali, é consagrada a intervenção como modalidade de trabalho final dos cursos. 
Assim, no sentido de compreender essa disposição de curso de pósgraduação stricto senso, é importante ressaltar a perspectiva da intervenção como aquela que enfatiza estudos diretamente voltados para a vida profissional dos mestrandos, no sentido de contribuir para o desenvolvimento da pesquisa relacionada com seu campo de atuação e que, na maioria das vezes, é desenvolvida diretamente no seu local de trabalho. Ou seja, é necessário que o pesquisador se debruce na análise de uma questão específica, que faz parte de seu universo profissional e carrega, portanto, marcas, posições, posicionamentos e relações de poder. Da inserção do pesquisador no cotidiano do campo empírico, origina-se um conjunto de questões que envolvem o pesquisador enquanto sujeito.

Severino (2019), ao tratar da consistência epistemológica e do compromisso ético da pesquisa em Educação, salienta em diferentes momentos a vinculação da pesquisa do campo educacional com o respeito à alteridade que necessariamente estará presente no processo e no percurso da pesquisa. Destaca que a observância a essa alteridade é o "fundamento de toda eticidade", sendo, ela mesma, a "portadora de dignidade própria da pessoa humana" (SEVERINO, 2019, p. 905). Ao se pensar a dimensão da intervenção na pesquisa, tais pressupostos adquirem ainda maior robustez na medida em que a pesquisa-intervenção se insere intensamente nos ambientes vivenciados e pesquisados. E é nesses ambientes que se estabelecem as relações e as intenções que se revelam nos processos, nos fenômenos, nos projetos que se efetivam como centrais na condução das investigações propostas. Nesse campo da prática, Severino (2019, p. 903) nos convoca a sermos atentos não só aos "requerimentos lógico-epistemológicos", mas também às "demandas éticas agudizadas".

A dimensão interventiva presente nas produções vinculadas aos Mestrados Profissionais suscita a necessidade de construções metodológicas capazes de coadunar os percursos já consagrados na literatura às peculiaridades institucionais dos espaços em que se pretende a intervenção. É neste cenário que a pesquisa intervenção vem construindo seus fundamentos e lidando com outras temporalidades e desafios.

É nesse contexto que assume especial relevância a questão de análise aqui proposta: perceber os desafios metodológicos presentes em uma pesquisa vinculada ao MP ao analisar seu próprio contexto profissional e a ele provocar uma reflexão interventiva, enfatizando a importância necessária da clareza epistemológica? 


\section{A pesquisa-intervenção nas dissertações produzidas}

A fim de compreender a maneira como a pesquisa-intervenção vem se constituindo enquanto proposição presente nas dissertações, foram analisadas todas as 100 produções de mestrandos concluintes do Programa de PósGraduação em Gestão Educacional - Mestrado Profissional (MPGE), da Universidade do Vale do Rio dos Sinos (Unisinos), no período compreendido entre 2014 e 2019. Todo o material analisado está disponível no repositório da instituição (UNISINOS, 2020). Os títulos, resumos, sumários, capítulo metodológico e proposta de intervenção (quando existente) foram retomados integralmente durante o levantamento realizado. A partir da leitura, os dados foram compilados em uma planilha, garantindo especial notoriedade aos seguintes itens: título do trabalho, autor(a), orientador(a), Linha de Pesquisa, ano de defesa, metodologia utilizada, proposta de intervenção, produção técnica identificada, palavras-chave, campo empírico, abrangência (local, regional, nacional ou internacional) e nível (unidade, rede ou sistema).

Antes de apresentar as produções e as análises aqui realizadas, é importante referenciar alguns elementos sobre a trajetória do MPGE da Unisinos. As articulações iniciais para a proposição do curso de Mestrado Profissional em Gestão Educacional são resultado da colaboração entre três Universidades, duas delas com larga e sólida experiência tanto na formação profissional e de pesquisadores quanto na formação continuada no campo da educação, entre outros campos afins à educação e à gestão. Coube, no entanto, à UNISINOS responsabilizarse pela proposição, gestão e pelo funcionamento do Curso, contando com as contribuições de duas outras instituições na disponibilização de professores, os quais permaneceriam na condição de professores colaboradores do MPGE. Atualmente, o corpo docente é composto apenas por professores da UNISINOS.

O MPGE destina-se à formação de mestres profissionais, tendo como público alvo egressos do ensino superior que sejam gestores educacionais e/ou professores (da escola básica, da educação profissional, do ensino superior), que atuam no amplo campo da educação em diferentes espaços profissionais, e profissionais de outras áreas que buscam formação na área de Educação para que possam desenvolver a gestão de grupos e/ou organizações privadas, públicas e não governamentais que estejam fundadas em princípios educativos.

Os egressos do MPGE caracterizam-se por serem profissionais que desempenham diferentes funções e cargos em universidades federais, estabelecimentos de ensino superior, Institutos Federais, escolas públicas e privadas de educação básica, estabelecimentos do Sistema S, ONGs, gestores de 
sistemas de ensino públicos estaduais e municipais de educação. São profissionais que atuam na chefia de serviços, departamentos ou de unidades, seja em redes ou em instituições, que compõem equipes diretivas em suas respectivas instituições, alguns como gestores(as), outros em função de apoio, outros ainda como docentes que se preparam para assumir responsabilidades administrativas. A formação em graduação é diversificada, incluindo licenciaturas em Letras, Filosofia, História, Pedagogia, e oriundos de cursos de Direito, Jornalismo, Informática, Administração, Engenharia, Agronomia, Biblioteconomia, Psicologia.

A área de abrangência do curso configurada pelo local de residência dos estudantes inclui várias cidades do Rio Grande do Sul, bem como profissionais que residem em outros estados da federação - Ceará, Piauí, Brasília, Santa Catarina, Minas Gerais, Paraná, Bahia, Rio de Janeiro, São Paulo - mas que frequentam regular e presencialmente o curso. Essa diversidade demonstra o interesse que a proposta pedagógica deste Mestrado Profissional em Gestão Educacional tem despertado em candidatos que enfrentam e superam questões de deslocamento e hospedagem para se titularem no MPGE da Unisinos; indica também o quanto os egressos levam suas aprendizagens para diferentes espaços profissionais no país. Tais elementos são importantes para compreendermos melhor as escolhas e as abordagens dadas aos trabalhos analisados na sequência.

No levantamento realizado, verifica-se um equilíbrio entre as produções advindas das duas linhas de pesquisa do Programa (Linha 1: Políticas e Sistemas Educacionais e Linha 2: Gestão da Educação Básica e Superior) a partir de 2017. Tal fato deve-se a um movimento de readequação do corpo docente entre as duas linhas, consolidando a atuação de professores e pesquisadores permanentes no Programa após o primeiro momento de construção e consolidação do MPGE.

\section{GRÁFICO 1 - LINHAS DE PESQUISA/ANO}

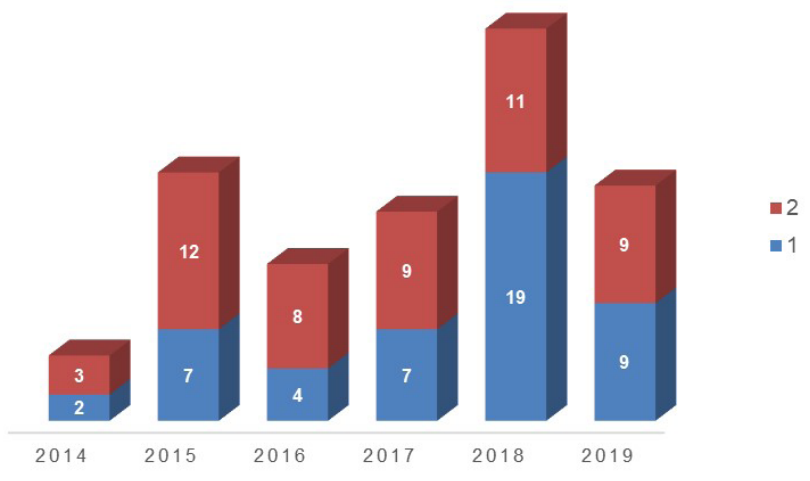

FONTE: Elaborado pelas autoras (2020). 
O aumento das propostas de intervenção verificado a partir de 2017, com um quantitativo ainda mais expressivo em 2018 está associado tanto ao amadurecimento de uma proposta que sempre esteve vinculada ao MPGE quanto à compreensão das especificidades de um trabalho de uma formação stricto sensu profissional. Evidentemente, o aumento das intervenções vincula-se também a uma estruturação específica do trabalho de conclusão, com a designação de um capítulo específico para as propostas, vinculado, mormente, a um objetivo específico igualmente vinculado a elas. Tal estrutura, importa observar, não desconsidera as considerações finais do trabalho e as propostas de continuidade, elementos que, nas primeiras produções, tomavam o lugar das intervenções ou confundiam-se com elas.

\section{GRÁFICO 2 - PROPOSTAS DE INTERVENÇÃO/ANO}

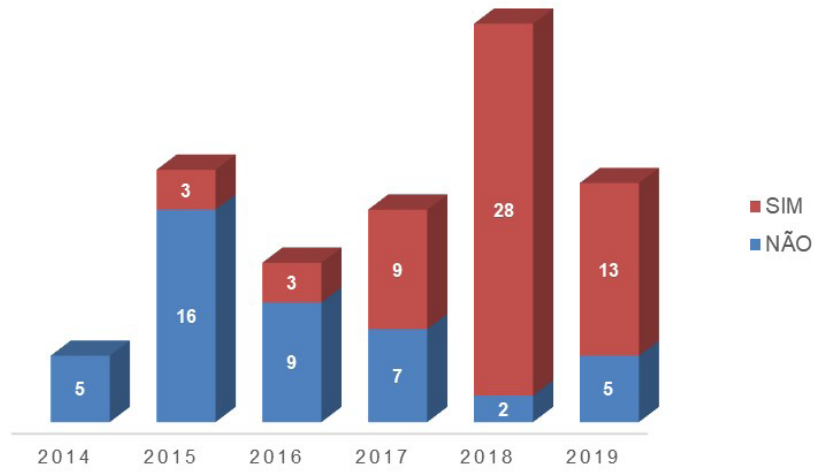

FONTE: Elaborado pelas autoras (2020).

Relativamente aos campos empíricos utilizados nos estudos, percebe-se um equilíbrio, ao longo do período analisado, entre os segmentos da Educação Superior pública e privada e da aqui designada educação não formal, onde são concentrados projetos específicos normalmente realizados por instituições privadas com fins não lucrativos ou com compromisso filantrópico. Tais projetos atendem populações mais carentes que se vinculam à instituição por diferentes motivos ou são oferecidos no contraturno a fim de atender a demandas específicas identificadas nas instituições pesquisadas. 


\section{GRÁFICO 3 - DEFESAS/CAMPO EMPÍRICO}
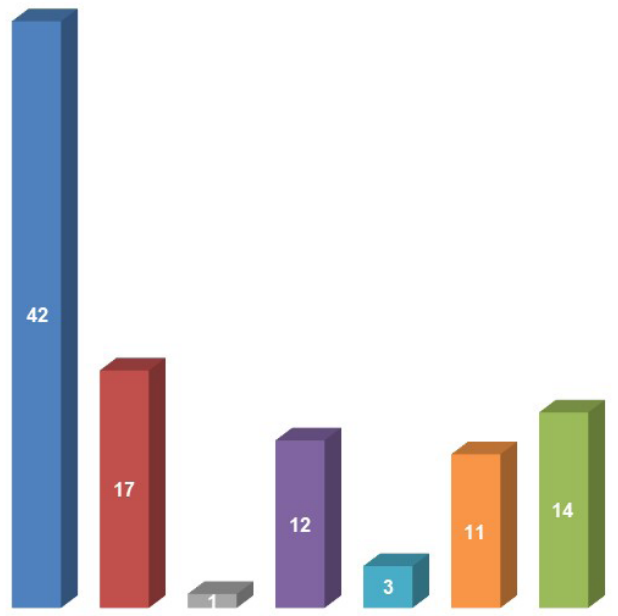

- Educação Básica Privada

- Educação Básica Pública

- Educação Básica Sistema "S"

- Educação não formal

- Educação Superior

n Educação Superior Privada

n Educação Superior Pública

FONTE: Elaborado pelas autoras (2020).

O quantitativo significativo da Educação Básica Privada está associado à existência das turmas complementares formadas por professores e gestores de escolas que integram a Rede Jesuíta de Educação e que estão espalhadas por todo o Brasil. Tal fato implica, também, no aumento das produções com abrangência regional e nacional que foram observadas nas dissertações analisadas e também nas temáticas relacionadas à gestão por redes e sistemas de ensino, como pode ser observado nos gráficos apresentados.

Para além dos aspectos quantitativos aqui apresentados - que oferecem indicadores interessantes acerca do processo de amadurecimento do curso, tanto no que tange às produções discentes quanto nos processos de orientação que acompanham e subsidiam tais produções - há que se pensar nas possibilidades e nos percursos qualitativos evidenciados por essas dissertações. Tal análise ainda não tem um estofo consistentemente constituído, mas uma leitura preliminar do levantamento, nos permite refletir um tanto sobre os sentidos da intervenção.

Inicialmente, para o projeto de pesquisa que trata o MP, temos insistido que o problema deriva da história/memória/vivência pessoal de cada pesquisador, ou seja, é a partir de onde este(a) se situa, das suas experiências, que pode haver uma problematização mais possível e, ao mesmo tempo, uma condição tão necessária quanto imprescindível de dar sequência ao referencial teórico em que se reconheça e daí coadunar com os fundamentos epistemológicos e com 
os procedimentos metodológicos, que juntos comporão o estudo em si. Isso nos parece ser um caminhar para um processo de pesquisa que responda de forma mais favorável à sua proposta de produzir um "novo" conhecimento sobre o fenômeno em questão.

A intervenção, por isso, não é fruto de um pensar solitário, de um saber único e individualizado sobre os demais. Ela surge do contexto da pesquisa, e nesse ponto, considerar "o conjunto de condições que circunscrevem o ato de pesquisar é o que lhe dá confiabilidade" (PAULON, 2005) e rigorosidade. Nesse sentido, o pesquisador há de ponderar ininterruptamente sobre seu ser/estar nela. Desse modo, ao pensarmos na intervenção, queremos pontuá-la a partir de Freire, que em sua obra, em sua contribuição e em seu encorajamento, moveu-nos para a direção de acreditar no papel transformador de nossa prática a partir dos atos reflexivos que se fazem dela. Por meio disso, mudanças são realizadas. Sendo assim, em seus estudos sobre a educação brasileira, parte de um conjunto rigoroso de análises e premissas. Para nos balizar nesse texto, destacaremos três delas. A primeira é a de que nossa cultura escolar, acadêmica, parte do pressuposto da ideia predominante nos discursos, seu ponto mais alto, seu "verdadeiro" fazer, ou seja, o que FREIRE (1981, p. 93) chega a chamar de "verbosidade". É uma ação que enfatiza a fala, uma tagarelice sem compromisso com o contexto em que se situa, sem considerar o outro que está no mesmo espaço. Uma fala que define a educação bancária, estando "desprendida da realidade, da existência do outro e de si [...]" (COSTA, 2018) que não comunica, não organiza um sentido, é palavra vazia, oca. Assim, também a pesquisa pode ser caracterizada como um discurso vazio, em que o autor prescreve um receituário de fórmulas, geralmente "mágicas" - produzindo um "discurso" aleatório.

Outra premissa é aquela que percebe o desenvolvimento histórico de nosso país (e que não se configura como um privilégio do pedaço do mundo em que estamos): uma formação social "clássica" que estabelece a dicotomia entre dominantes e dominados, ou como preferia Freire, opressores e oprimidos (FREIRE, 1987). Aqui damos relevância àquelas que se expressam na naturalização das injustiças e das desigualdades, as quais são reconhecidas por Freire (2000, p. 54) como forças imobilizadoras, presentes em nosso cotidiano. Como afirma, "não há atualidade que não seja palco de confrontações entre forças que reagem ao avanço e forças que por ele se batem." (FREIRE, 2000, p. 54). É esse contexto que segue marcando nossa luta diária em pleno século XXI. Isso tudo, por certo, traduz-se na negação da liberdade e de tudo que advém dela.

A última premissa aqui sugerida como imprescindível é aquela que reconhece que homens e mulheres são seres posicionados. Não há neutralidade em nossas ações, em nossas crenças, em nossa postura. Nossa presença no mundo não é neutra (FREIRE, 1979). Assim, não há sujeitos neutros no desenvolvimento 
da pesquisa, e nem em qualquer outro espaço em que se encontrem. O que há, são sujeitos "comprometidos" contra outros homens e mulheres (FREIRE, 1979).

A partir do ponto de que nos vemos não neutros e cheios de possibilidades, retomamos ao que seria a pesquisa. E, na sequência, ao que configura a intervenção. É a partir do sentido adquirido na intenção de que as palavras guardam significado. Daí, por óbvio, há de ser problematizado o termo intervenção. Desse modo, com o que já afirmamos, o primeiro corte que estamos defendendo ocorre com o "sujeito interventor". Não é de interventor que a pesquisa-interventiva se pensa e se faz. Daí a importância de refletirmos sobre o problema de pesquisa, como já mencionado anteriormente, o qual se origina da primeira proposição destacada anteriormente, pois num mundo de "verbosidades", de falas que não estão encharcadas de uma reflexão sobre sua prática, está caracterizado o pensar descomprometido sobre seu contexto histórico-político-social e a ponderação sobre sua própria experiência. Tal prática é desnecessária, irrelevante e dispensável para uma pesquisa que se quer comprometida com a vida para todos e todas. Bondía (2002, p. 20-21), quando do convite de tratar sobre o que seria, no contexto educacional, a "experiência/ sentido", partiu do entendimento de que "A experiência é o que nos passa, o que nos acontece, o que nos toca. Não o que se passa, não o que acontece, ou o que toca". Diante disso, perguntamo-nos sobre o que seria a pesquisa nessa referência. Seguindo nosso caminho "existente-pensante", sobre a segunda premissa trazida, acerca da naturalização da desigualdade, da inexistência do direito para homens e mulheres, questionamos, igualmente, o que seria o papel, os objetivos da pesquisa nas humanidades.

A terceira ideia trazida a partir de Freire (1979) vem de alguma forma ponderar o caráter ideológico das crenças efetivadas nos dois primeiros princípios. A não existência da neutralidade faz-nos compreender que, quando pensamos no desenvolvimento da pesquisa, há por certo um conjunto de pressupostos que queremos fortalecer. Porém, se desencarnados do contexto e dos demais sujeitos, ela corresponderá aos desígnios indicados nesses dois primeiros argumentos sugeridos inicialmente.

Se iniciarmos daqui o debate sobre intervenção, teríamos inicialmente que considerar nossas intencionalidades, nossa dialogicidade a partir da nossa compreensão sobre o mundo.

Daí depreendemos que, para Freire (2000), a intervenção se constitui em um conceito que se opõe à acomodação e ao determinismo. Ao contrário, se alicerça no sonho e na luta. "O futuro não nos faz. Nós é que nos refazemos na luta para fazê-lo" (FREIRE, 2000, p. 56). Desse modo, a intervenção é uma possibilidade de sermo-nos sonho e luta na realidade. De maneira inversa, porque não podemos ser ingênuos, a intervenção, perspectivada sobre as 
duas primeiras premissas (o ser/estar reflexivo do pesquisador na pesquisa e a condição histórica de nossa realidade), é um paradigma que se faz sobre a lógica autoritária, prepotente e arbitrária, em que uns determinam como única saída aos demais. Essa perspectiva nega o sonho e a luta. Freire (2000, p. 61), portanto, descreve o papel interventivo de uma ação, a partir do caráter dicotômico da palavra intervenção, pois pode servir tanto para a "reprodução da ideologia dominante quanto ao seu desmascaramento". O que coloca-se aqui é o lugar que ocupamos nesse contexto.

Por isso, é tão necessário articularmos todo esse debate às questões metodológicas e teóricas, isto é, no necessário debate acerca da pesquisa em si - para quê, o que é, com quem acontece, como se desenvolve, quais seus passos, o que lhe é imprescindível. Assim, como já afirmamos, se a pesquisa é algo que ocorre entre pesquisador(a) e campo de pesquisa, e não do primeiro sobre o segundo, há uma relação entre ambos, o que vem corroborar com a ideia da confiabilidade, rigorosidade e cientificidade do processo interventivo. Nessa síntese, não há interventor, há uma possível ação de modificação da realidade, seu contexto e seu cotidiano, porque homens e mulheres foram provocados a refletirem sobre si, sua profissionalidade, seu lugar de trabalho. É desse modo que o papel crucial do pesquisador para Luna (2010) é desencadear o problema, formular as questões, tecer o projeto e seus procedimentos, sempre na perspectiva do que o autor denomina experiência vivida. Trata-se de "acompanhar um processo, e não representar um objeto" (KASTRUP, 2007, p. 15). Com essa premissa, rompe-se com uma perspectiva institucionalista e avança-se em direção à análise institucional, o que supõe uma superação de uma perspectiva meramente descritiva e que, em alguns momentos, busca somente a chancela acadêmica para uma solução que já estava elaborada ou mesmo implantada. É a partir disso, também, que se avança para o "plano implicacional" (PASSOS; BARROS, 2009), onde "as posições de quem conhece e do que é conhecido, de quem analisa e do que é analisado se dissolvem na dinâmica de propagação das forças instituintes característica dos processos de institucionalização." (PASSOS; BARROS, 2009, p. 25).

\section{Compreensões, conclusões e continuidades possíveis}

Os trabalhos analisados, com ênfase nos que apresentam proposta de intervenção sistematizada, permitem algumas inferências acerca das suas opções metodológicas e acerca do formato garantido à intervenção. Existe ali uma 
incidência múltipla de análises quantitativas e qualitativas, com prevalência desta última. A recorrência dos estudos de caso vigora ao lado de opções por revisões documentais e até mesmo bibliográficas. As entrevistas e questionários também aparecem com frequência, evidenciando a valorização das diferentes atuações nos cenários analisados e os diferentes posicionamentos que elas podem assumir frente à situação investigada.

Tais encaminhamentos reforçam a busca por um método de investigação que esteja em sintonia com o caráter processual da investigação, dentro da perspectiva da pesquisa-intervenção. Percebe-se, ainda, nos trabalhos analisados, "a inseparabilidade entre conhecer e fazer, entre pesquisar e intervir" (PASSOS; BARROS, 2009, p. 17), o que caracteriza as pesquisas analisadas como intervenções.

Para além desses elementos, nos interessa aqui mais diretamente avançar na observação da forma como os trabalhos se coadunam em torno das propostas de intervenção. A diversidade das proposições com que as dissertações trabalham derivam da multiplicidade dos espaços analisados, das diferentes atuações e formações dos pesquisadores envolvidos e também da busca por estratégias diferenciadas - porém nunca dissonantes dos espaços de onde emergem capazes de respeitar as ordenações já vigentes e de avançar a partir delas, rumo a possibilidades mais interessantes frente ao trabalho proposto. Tais possibilidades e tensionamentos são fruto da problematização de uma situação vivida - essencial para o ato de pesquisar - e que reside, na dicotomia proposta por Freire sobre a intervenção, na lógica do desmascaramento.

A naturalização das relações estabelecidas no desenvolvimento histórico brasileiro, conforme referido por Freire (1987), encontra frentes de rebatimento nas propostas de intervenção desenhadas pelas dissertações. Na medida em que são propostos novos formatos, novas configurações, novas leituras para determinadas dinâmicas, desnaturalizam-se padrões, ousando fazer de um jeito diferente o que vinha sendo feito e possibilitando o redimensionamento das relações estabelecidas nos ambientes analisados.

O posicionamento igualmente evocado por Freire (1979) parece encontrar espaço nos trabalhos aqui analisados. A superação da neutralidade frente a alguns processos e a assunção de uma postura investigativa aliada à práxis constitui um desafio assumido pelas intervenções apresentadas. Percebe-se, portanto, que não se trata do sujeito interventor anteriormente referido, mas da reflexão a partir de um problema de pesquisa que nos convida a revisitar práticas, buscando definir suas potencialidades e suas fragilidades, e a refletir sobre novas possibilidades de atuação. 
Parte-se, assim, da necessidade de a intervenção emergir a partir do lugar de atuação do pesquisador, garantindo legitimidade ética e epistemológica às propostas formuladas. É nesse lugar que reside a capacidade de refletir sobre o problema de pesquisa, garantindo ao processo de pesquisa uma dimensão socialmente comprometida e não o caráter de soluções únicas capazes de atender a situações supostamente padronizadas.

Outro elemento que merece destaque diz respeito ao processo de amadurecimento das propostas de intervenção. Nos trabalhos analisados, é observável uma apropriação da intervenção que pode ser designada como orgânica, ou seja, que se apresenta intimamente vinculada ao trabalho e não como um apêndice que atende a uma obrigatoriedade de formato. Entende-se, com isso, o avanço da própria proposição de um Mestrado Profissional, que mostra-se mais capacitado para assumir com vigor as exigências vinculadas à formação oferecida.

Por fim, é fundamental uma menção à maneira como a constituição da pesquisa-intervenção se coaduna ao próprio fortalecimento do campo da gestão educacional no Brasil. Se no início desse artigo, apontávamos para a necessidade de alguns amadurecimentos no campo do stricto sensu profissional, ousamos encerrar essa escrita com a afirmação de que o avanço no campo da intervenção "aponta inevitavelmente para a necessidade da configuração do campo da gestão educacional e escolar (KLAUS; GHISLENI 2018, p. 25). O desafio é seguir forjando essa configuração sem afastar a gestão educacional da sua área de conhecimento, que é a educação.

\section{REFERÊNCIAS}

ANDRÉ, Marli e PRINCEPE, Lisandra. O lugar da pesquisa no Mestrado Profissional em Educação. Educar em Revista, Curitiba, n. 63, p. 103-117, jan./mar. 2017. Disponível em: https://www.scielo.br/scielo.php?pid=S0104-40602017000100103\&script=sci_ abstract\&tlng=pt. Acesso em: 15 fev. 2021.

BONDÍA, Jorge Larrosa. Notas sobre a experiência e o saber de experiência. Revista Brasileira de Educação. Rio de Janeiro, n. 19. p. 20-28, jan./abr. 2002. Disponível em: https://www.scielo.br/pdf/rbedu/n19/n19a02.pdf. Acesso em: 23 mar. 2021.

CAPES. Portaria Normativa $n^{\circ} 17$, de 28 de dezembro de 2009. Dispõe sobre o mestrado profissional no âmbito da Fundação Coordenação de Aperfeiçoamento de Pessoal de Nível Superior-CAPES. Disponível em: http://www.anped11.uerj.br/portarianormativa_no1728.12.2009-mestradoprofissional.pdf. Acesso em: 21 abr. 2021. 
COSTA, Daianny Madalena. Comprometimento. In: STRECK, Danilo R.; REDIN, Euclides; ZITKOSKI, Jaime José (org.). Dicionário Paulo Freire. Belo Horizonte: Autêntica, 2018. p. 93-94.

CUNHA, Maria Isabel da. A formação docente na universidade e a ressignificação do senso comum. Educar em Revista, Curitiba, v. 35, n. 75, p. 121-133, maio/jun. 2019. Disponível em: https://revistas.ufpr.br/educar/article/view/67029. Acesso em: 23 mar. 2021.

FREIRE, Paulo. Educação e mudança. 2. ed. Rio de Janeiro: Paz e Terra, 1979.

FREIRE, Paulo. Educação como prática da liberdade. 12. ed. Rio de Janeiro: Editora Paz e Terra. 1981.

FREIRE, Paulo. Pedagogia do oprimido.17. ed. Rio de Janeiro: Paz e Terra, 1987.

FREIRE, Paulo. Pedagogia da indignação: cartas pedagógicas e outros escritos. São Paulo: Editora UNESP, 2000.

GATTI, Bernardete A. Pesquisa em educação: um tema em debate. Cadernos de Pesquisa . São Paulo, n. 80, p. 106-111, fev. 1992. Disponível em: http://publicacoes.fcc.org.br// index.php/cp/article/view/1009. Acesso em: 23 mar. 2021.

KASTRUP, Virgínia. O funcionamento da atenção no trabalho do cartógrafo. Psicologia \& Sociedade. Recife, v. 19, n. 1, p. 15-22, jan/abr. 2007. Disponível em: https://www. scielo.br/scielo.php?pid=S0102-71822007000100003\&script=sci_abstract\&tlng=pt. Acesso em: 21 abr. 2021

KLAUS, Viviane; GHISLENI, Ana Cristina. Gestão educacional e escolar: sobre o campo de estudos e seus desafios contemporâneos. In: QUIOSSA, Amanda Sangy et al. Diálogos e Proposições. Juiz de Fora: Fadepe/CAEd, 2018. p. 25-34. v. 3.

LUNA, Sérgio Vasconcelos de. O falso conflito entre tendências metodológicas. In: FAZENDA, Ivani (org.). Metodologia da pesquisa educacional. São Paulo: Cortez, 2010. p. 23-38.

MAINARDES, Jefferson. A pesquisa no campo da política educacional: perspectivas teórico-epistemológicas e o lugar do pluralismo. Revista Brasileira de Educação, Rio de Janeiro, v. 23, e230034. p. 1-20, 2018. Disponível em: https://www.scielo.br/scielo. php?script=sci_arttext\&pid=S1413-24782018000100227\&lng=pt\&nrm=iso\&tlng=pt. Acesso em: 23 mar. 2021.

MAZZOTTI, Alda Judith Alves. Impacto da pesquisa educacional sobre as práticas escolares. In: ZAGO, Nadir; CARVALHO, Marília Pinto de; VILELA, Rita Amélia Teixeira (org.). Itinerários de pesquisa: perspectivas qualitativas em sociologia da educação. Rio de Janeiro: DP\&A, 2003. p. 33-48.

PASSOS, Eduardo e BARROS, Regina Benevides de. A cartografia como método da pesquisa-intervenção. In: PASSOS, Eduardo; KASTRUP, Virgínia; ESCÓSSIA, Liliana da (org.). Pistas do método da cartografia. Porto Alegre: Sulina, 2009. p. 17-31 
PAULON, Simone Mainieri. A análise de implicação como ferramenta na pesquisaintervenção. Psicologia \& Sociedade, Recife, v. 17, n. 3, p. 18-25. 2005. Disponível em: https://www.scielo.br/scielo.php?script=sci_abstract\&pid=S0102-71822005000300003\&ln $\mathrm{g}=\mathrm{en} \& \mathrm{nrm}=$ iso\&tlng=pt. Acesso em: 23 mar. 2021.

SEVERINO, Antônio Joaquim. Pesquisa educacional: da consistência epistemológica ao compromisso ético. Revista Ibero-Americana de Estudos em Educação, Araraquara, v. 14, n. 3, p. 900-916, jul./set. 2019. Disponível em: https://periodicos.fclar.unesp.br/ iberoamericana/article/view/12445. Acesso em: 23 mar. 2021.

UNISINOS. Mestrado Profissional em Gestão Ambiental. Disponível em: http://www. unisinos.br/mestrado-profissional/gestao-educacional/presencial/porto-alegre/teses-edissertacoes. Acesso em: 2020.

Texto recebido em $03 / 03 / 2021$.

Texto aprovado em 21/04/2021. 